\title{
Red-Near Infrared Luminescence Detection of Latent Fingermarks with Heavy-Metal-Free Quantum Dots
}

\author{
Sorour Shahbazi, ${ }^{[a]}$ Braden Grant, ${ }^{[a]}$ Dechao Chen, ${ }^{[a]}$ Thomas Becker ${ }^{[a]}$ Guohua Jia, ${ }^{*[a]}$ Simon W. \\ Lewis $^{*[a]}$
}

\begin{abstract}
Current and proposed nanoparticle-based techniques for development of latent fingermarks suffer a number of drawbacks such as complicated, multi-step and time-consuming procedures, batch-tobatch variability, expensive reagents, large background noise and toxicity. Here, we introduce a promising green development technique based on heavy-metal-free quantum dots for the detection of latent fingermarks on non-porous surfaces. Red-near infrared luminescent Cu-In-S/ZnS core-shell QDs solution was produced in large scales using a water-based, simple and fast method using $\mathrm{N}$-acetyl-cysteine as a biocompatible surfactant to coat the particles. The coated QDs were applied to the successful development of latent fingermarks deposited on a variety of surfaces, including highly patterned polymer banknotes and the sticky side of adhesive tape.
\end{abstract}

The detection of latent fingermarks has been carried out in forensic science for more than a century to reveal the connection between individuals and objects found at crime scenes. ${ }^{[1]}$ Innovative methods and materials based on nanotechnology have seen noticeable progress and expanded new horizons in the specific targeting of fingermark components. ${ }^{[2]}$ Luminescent quantum dots (QDs) manifesting large cross section in the UV/visible spectral range, narrow and size-dependent emission wavelength, high quantum efficiency, and enhanced photostability, have been applied to the development of latent fingermarks over the last two decades. ${ }^{[3]}$ Although cadmiumbased QDs such as $\mathrm{CdS},{ }^{[3 a]} \mathrm{CdSe}^{[4]}$ and $\mathrm{CdTe}^{[5]}$ have successfully visualised the latent fingermarks, carcinogenic issues associated with heavy metals have always been a concern. ${ }^{[6]}$ Some reported methods to increase their biocompatibility have included covering them with a surfactant or overcoating them with a non-toxic inorganic shell, ${ }^{[7]}$ however, with these techniques, the toxicity issue remains unsolved. As an alternative, using heavy-metal-free QDs such as carbon ${ }^{[8]}$ and $\mathrm{Cu}$ - and $\mathrm{Mn}$-doped $\mathrm{ZnS}^{[9]}$ dots has been proposed, however, the latent fingermarks visualised by these QDs which luminesce in the visible part of the spectrum, exhibited reduced sensitivity of the detection due to background noise. ${ }^{[8-9]}$

An important consideration when selecting a fingermark detection technique is the nature of the substrate. Photoluminescent materials are more suitable options when dealing with dark, multicoloured or patterned substrates. Luminescence increases the contrast between latent fingermark ridges and the underlying substrate by moving the means of detection outside of the ambient illumination. ${ }^{[10]}$ Materials luminescing at a longer

[a] S. Shahbazi, B. Grant, D. Chen, Dr T. Becker Dr. G. Jia, Prof. S. W. Lewis

Curtin Institute of Functional Molecules and Interfaces

School of Molecular and Life Sciences

Curtin University

GPO Box U1987, Perth, WA, 6845

E-mail: s.lewis@curtin.edu.au; guohua.jia@curtin.edu.au

†Electronic supplementary information (ESI) for this article is available wavelength, preferably in the near infrared (NIR) region, have the potential to improve detectability of fingermarks since there is less interference in this region. However, only a limited number of NIRbased techniques have been reported for the detection of fingermarks and these techniques suffered drawbacks including toxicity, being a post treatment rether than a standalone process and lack of contrast. ${ }^{[11]}$

To fill this technology gap, three main objectives were established to be achieved: first, preparation of a red-NIR luminescent heavymetal-free QDs water-based solution, second, modification of the QDs to boost their affinity to interact with the fingermark residue and third, making the procedure simple and practical for operational use.

As a low toxic ternary metal complex chalcogenide, Cu-In-S/ZnS (CIS-ZS) core-shell quantum dots have a strong and broad absorption, intense emission and reasonable stability under photoexcitation. ${ }^{[12]}$ CIS-ZS QDs have been used in a variety of light-emitting applications such as solar cells, ${ }^{[13]}$ electroluminosity, ${ }^{[14]}$ photocatalysts ${ }^{[15]}$ and bio-imaging. ${ }^{[16]}$ However, to the best of our knowledge, ternary core-shell QDs with photoluminescence $(\mathrm{PL})$ in red/NIR range have not been used for fingermark visualisation.

Synthesis of QDs in an organic phase produces uniform and brightly luminescent products. However, an organic synthesis method is complicated, time-consuming and expensive due to the tedious preparation steps, inert atmosphere condition, and high reaction temperature $\left(>200^{\circ} \mathrm{C}\right) \cdot .^{[16 a, 16 c, 17]}$ Also, the yield of QDs is very low ( tens of $\mathrm{mg}$ ) and the required organic substances raise significant safety issues. ${ }^{[16 a, 18]}$ Furthermore, as a post-synthesis treatment, QDs must be transferred from organic to aqueous phase by ligand exchange to render them biocompatible and applicable for fingermark development, which is a long process and may result in agglomeration and loss of luminescence. ${ }^{[5 a, 16 a]}$ We experienced all the aforementioned issues during the organicsynthesis and ligand exchange of the CIS-ZS QDs as well as their application for fingermarks development (See ESI†, Figure S1 and Figure $\mathrm{S} 2$ for more experimental details and results). These drawbacks limit the usage of this method in real-world cases. Preparation of QDs in water is faster, simpler, more biocompatible and inexpensive. ${ }^{[16 a]}$ However, the surfaces of the as-prepared QDs have dangling bonds and are tentatively passivated by organic surfactants. Thus, exposure of QDs to an aqueous environment results in surface oxidation and a decrease in luminescence efficiency. ${ }^{[17]}$ Previous studies used nitrogen gas purging to solve the problem but this method cannot completely suppress the quenching effect. ${ }^{[9 a}$, 18a] As a more effective strategy, passivation of QDs with an inorganic shell made of other semiconductor materials noticeably minimises the trap-state defects and increases the luminescent quantum yield and stability. ${ }^{[16 a, 19]}$

Aqueous-synthesis of CIS-ZS using microwave-assisted ${ }^{[16 c]}$ and hydrothermal ${ }^{[16 b]}$ methods suffer drawbacks including the necessity of special facilities and being a time consuming procedure. Most recently, a convenient, fast and inexpensive 
water-based synthesis method with a possibility of upscaling has been established to produce CIS-ZS QDs in safer way (Scheme 1). ${ }^{[12 b, 16 a]}$ In this technique, a mixture of copper, indium and sulfur precursors in water is heated at low temperatures $\left(<100^{\circ} \mathrm{C}\right)$ to produce the $\mathrm{Cu}-\mathrm{In}-\mathrm{S}$ core, and then a zinc precursor is added to form the shell around the cores. In this work, the latter method with some modifications was used to produce large amounts of $(3.1 \mathrm{~g})$ CIS-ZS QDs. The produced CIS-ZS solution was used directly for the effective visualisation of latent fingermarks on different non-porous substrates without any further changes such as purification or $\mathrm{pH}$ and temperature adjustments.

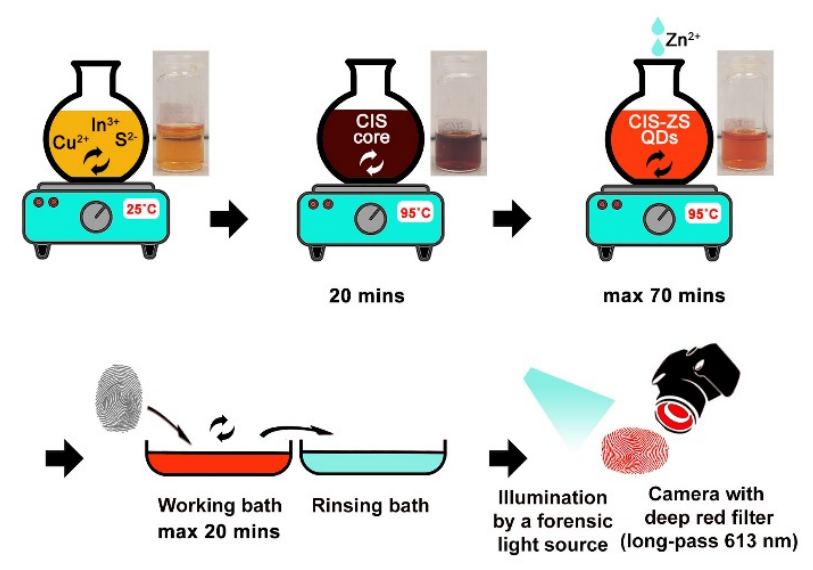

Scheme 1. Schematic illustration of production of fluorescent CIS-ZS core-shell QDs working solution and its application for visualising latent fingermarks.

Colloidal CIS-ZS core-shell QDs were synthesised in water in a simple one-step technique. First, aqueous solutions of $\mathrm{CuCl}_{2}$, $\mathrm{InCl}_{3}, \mathrm{Na}_{2} \mathrm{~S}$ were mixed in water in presence of a surfactant and ammonium solution. The reaction mixture was heated up and kept at $90-95^{\circ} \mathrm{C}$ (Scheme 1, see ESI† for experimental details). Cu and In salts participate in a precipitation reaction with sodium sulfide and produce the Cu-In-S spherical nanoparticles. ${ }^{[17]}$ In the next step, Zn (II) precursor was added to the reaction mixture without any purification and the $\mathrm{ZnS}$ layers epitaxially grew on the cores as a shell and produce a luminescent CIS-ZS QDs solution (Figures 1a-1c). This QDs solution can be prepared within $90 \mathrm{~min}$ on a large scale (at least $400 \mathrm{ml}$ of $0.96 \mathrm{M}$ solution per batch). Figure 1d and Figures S3a-S3d show the TEM images of the synthesised CIS-ZS core-shell QDs. The size of the QDs was less than $5 \mathrm{~nm}$. Absorption (Ab) and PL spectra of the CIS core and CIS-ZS core-shell QDs are illustrated in Figure 1e. The synthesised QDs fluoresced at deep red to NIR (emission maximum at $660 \mathrm{~nm}$ ) when excited in a wide range of wavelengths from UV to red region. The growth of $\mathrm{ZnS}$ shells around the CIS cores noticeably increased the PL intensity (approximately 15 times). Increasing the amount of $\mathrm{Zn}^{2+}$ precursor resulted in significant enhancement of the luminosity due to an increase of the thickness of the shell (Inset in Figure 1e); however, it led to a slightly blue-shift from $680 \mathrm{~nm}$ for the core to $660 \mathrm{~nm}$ for the final product. This is most probably related to the surface reconstruction rather than the diffusion of $\mathrm{Zn}$ into the $\mathrm{CIS}$ core taking into account the relatively low temperature of $90-95{ }^{\circ} \mathrm{C} .{ }^{[16 \mathrm{~d}]}$
Aging the prepared QDs solution under light for about one month, noticeably boosted the PL intensity (Figure S3e) because of the photodegradation of the surfactant leading to thickening the shell, increasing the crystallinity and reducing the surface defects, as reported previously. ${ }^{[18 a, 20]}$
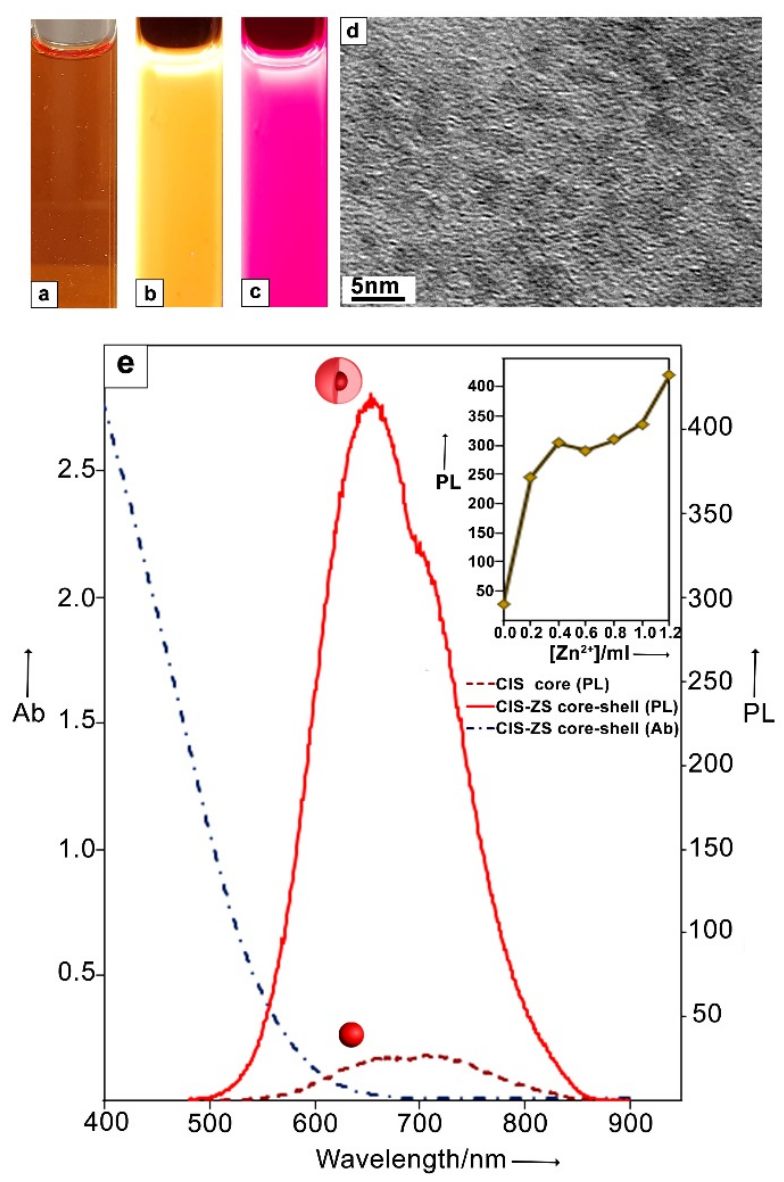

Figure 1. (a-c) CIS-ZS QDs solution photographed under (a) no illumination and (b and c) $350 \mathrm{~nm}$ illumination and through ( $\mathrm{a}$ and b) no filter and (c) deep red filter (long-pass $613 \mathrm{~nm}$ ). (d) TEM image of CIS-ZS QDs. (e) PL (excited at 350 $\mathrm{nm})$ and $\mathrm{Ab}$ spectra of CIS core and CIS-ZS core-shell QDs. Inset in (e): maximum (excited at $350 \mathrm{~nm}$ ) PL of CIS-ZS QDs with different amounts of $\mathrm{Zn}^{2+}$ precursor $\left(\left[\mathrm{Zn}^{2+}\right]\right)$.

A typical procedure for the treatment of latent fingermarks with CIS-ZS QDs solution is illustrated in Scheme 1. To validate the technique, the natural split fingermarks of 8 donors (3-days-old and 11-days-old) on glass slides were developed. The marks were shaken in the solution for maximum of $20 \mathrm{~min}$. International Fingerprint Research Group (IFRG) guidelines relating to initial proof of concept (Phase 1) studies were followed to conduct the experiment (see ESI† for experimental details). ${ }^{[21]}$ The results demonstrated development of the marks ridge details for the majority of the marks (Figure S4).

Addition of more than $0.6 \mathrm{ml}$ of $\mathrm{Zn}$ precursor led to the formation of a cloudy solution due to agglomeration and precipitation of the QDs. Although this unstable solution was suitable for treatment of fingermarks on heavy substrates such as glass slides which could 
be placed at the bottom of bath, it was difficult to be used for light substrates such as banknotes and aluminium foil as they did not settle at the bottom of the bath. Therefore, the fingermarks on these substrates were not in contact with enough QDs and were not developed satisfyingly. To tackle this issue, the prepared solution was stabilised with 3-mercaptopropionic acid (MPA) surfactant (the same surfactant used during the synthesis) as a post-synthesis step to prevent sedimentation of the dots (Figures S5). As a proof of concept, several charged latent fingermarks on new Australian polymer banknote and aluminium drink can as nonporous multi-coloured substrates were treated and developed well enough to distinguish a high levels of ridge detail (Figure 2). Being luminescent in deep red to NIR region made it possible to visualise the latent fingermarks on these multi-coloured and multipatterned substrates. Successfully developed charged and natural split fingermarks on other substrates including glass slides and transparent sticky tape are shown in Figure S6.
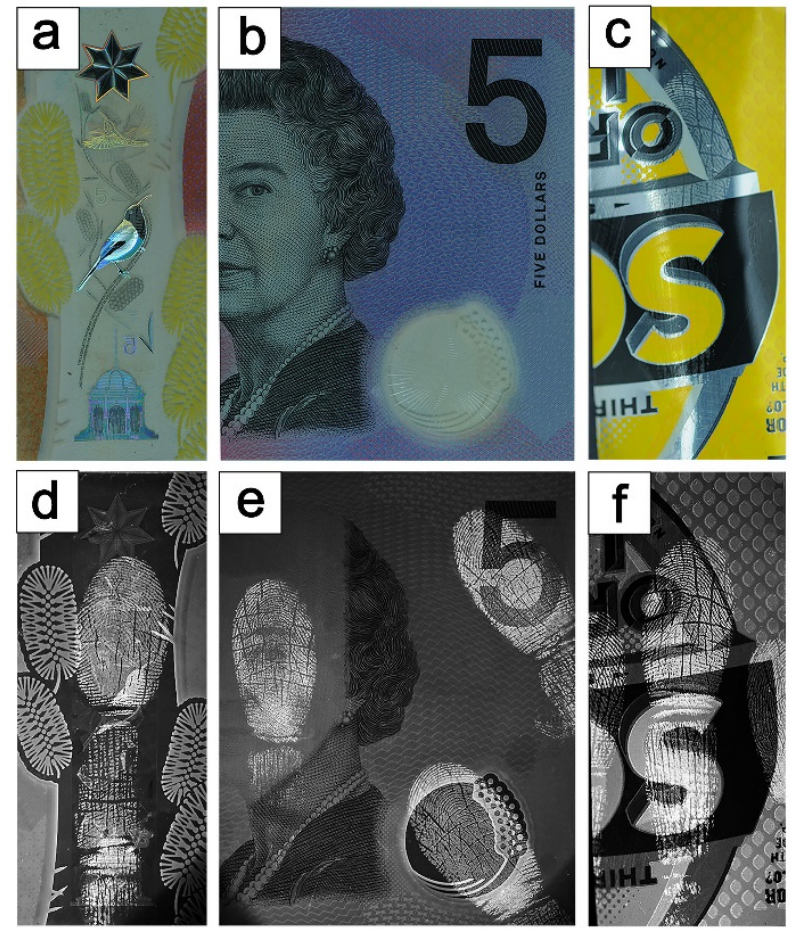

Figure 2. (a-c) Unilluminated and (d-f) illuminated (at $350 \mathrm{~nm}$ ) developed charged latent fingermarks (one female donor) deposited on Australian polymer banknote ( $a, b, d$ and $e$ ) and aluminium drink can ( $c$ and $f$ ). The illuminated marks were pictured through a deep red filter. The marks were shaken at 20 rpm for $20 \mathrm{~min}$ in a MPA-coated CIS-ZS QDs solution. See ESI† and Table S1 for the photography details.

As a unique characteristic, QDs can be excited in a broad range of wavelength, which makes it possible to visualise the fingermarks illuminated at different wavelengths. Figure 3 shows that the UV-fluorescent bird interfered with the fingermark on top of it (Figure $3 b$ ). To visualise the hidden part of the fingermark, it was illuminated at $450 \mathrm{~nm}$ instead of $350 \mathrm{~nm}$ leading to the elimination of fluorescence caused by the dye used for the bird (Figure 3c). Despite the satisfying development of the charged fingermarks on the banknote and the drink can, natural fingermarks on these substrates were not at all or only partially developed using this technique (Figure S7). However, the QDs provided the high-quality development of the natural fingermarks on the adhesive side of sticky tapes, which are traditionally challenging substrates for fingermark detection (Figure S8). Magic sticky tape fluoresces in UV and benefited from the longwavelength luminosity of the CIS-ZS QDs as the background interface was removed using the deep red filter and Wratten gelatin filter no. 29 (Figure S8a).

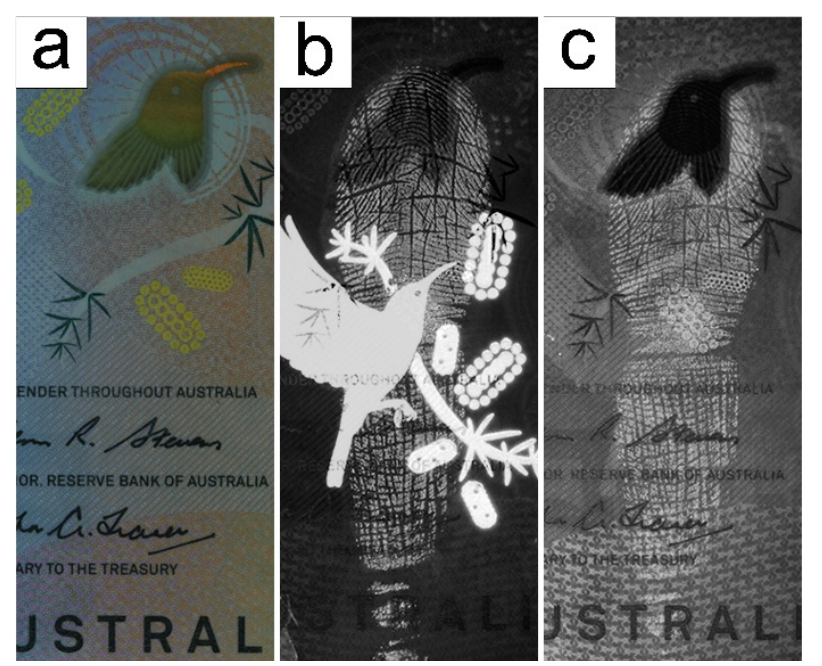

Figure 3. Treated charged latent fingermark (one female donor) on the Australian polymer banknote (a) unilluminated and illuminated at (b) $350 \mathrm{~nm}$ and (c) $450 \mathrm{~nm}$. Illuminated mark was pictured through a deep red filter. The mark was shaken at $20 \mathrm{rpm}$ for $20 \mathrm{~min}$ in MPA-coated CIS-ZS QDs solution. See ESIT and Table S1 for the photography details.

MPA as a bifunctional surfactant was added during and after the synthesis of the CIS-ZS QDs to provide an electrostatic shield against inter-particle interactions and prevents sedimentation of the QDs in water. ${ }^{[12 a]}$ Also, the long carbon chain and carboxylic group in the chemical structure of MPA increases both polar and non-polar interaction affinity with the components within fingermark secretions. However, MPA is a toxic and malodorous chemical. To increase the safety of the working solution, MPA was replaced with $\mathrm{N}$-acetyl-cysteine (NAC) in the post-synthesis step. NAC is a green and non-hazardous chemical and is used for medical purposes such treatment of paracetamol poisoning ${ }^{[22]} \mathrm{Xu}$ et al. demonstrated that NAC-capped QDs developed more ridge details of latent fingermarks compared to other ligands including MPA. ${ }^{\left[{ }^{9 b}\right]}$ This is due to the variety of functional groups present in NAC, such as thiols, carbonyl and amide groups which enable interactions with lipids and amino acids present in fingermark secretions. Figure 4 shows a high ridge detail including the sweat pores of a natural latent fingermark on a transparent sticky tap developed with the NAC-coated CIS-ZS core-shell QDs. It was found that the development time can be decreased from 15 min to $5 \mathrm{~min}$ for the marks on the sticky tapes, in all likelihood due to the presence of a greater amount of fingermark residue left on the adhesive side of the sticky tapes. Figure S9 illustrates visualised split natural and charged latent fingermarks on other substrates 
including black and blue adhesive insulating tapes, aluminium foil, aluminum drink can and zip-lock bag. Remarkably, a fresh natural fingermark on a blue adhesive insulating tape was developed without shaking (Figure S8d). To further investigate potential of the technique, the natural split fingermarks of 6 donors (3-daysold) on aluminium foil were developed. The results demonstrated full or partial development of the latent fingermarks from all 6 donors (Figure S10).

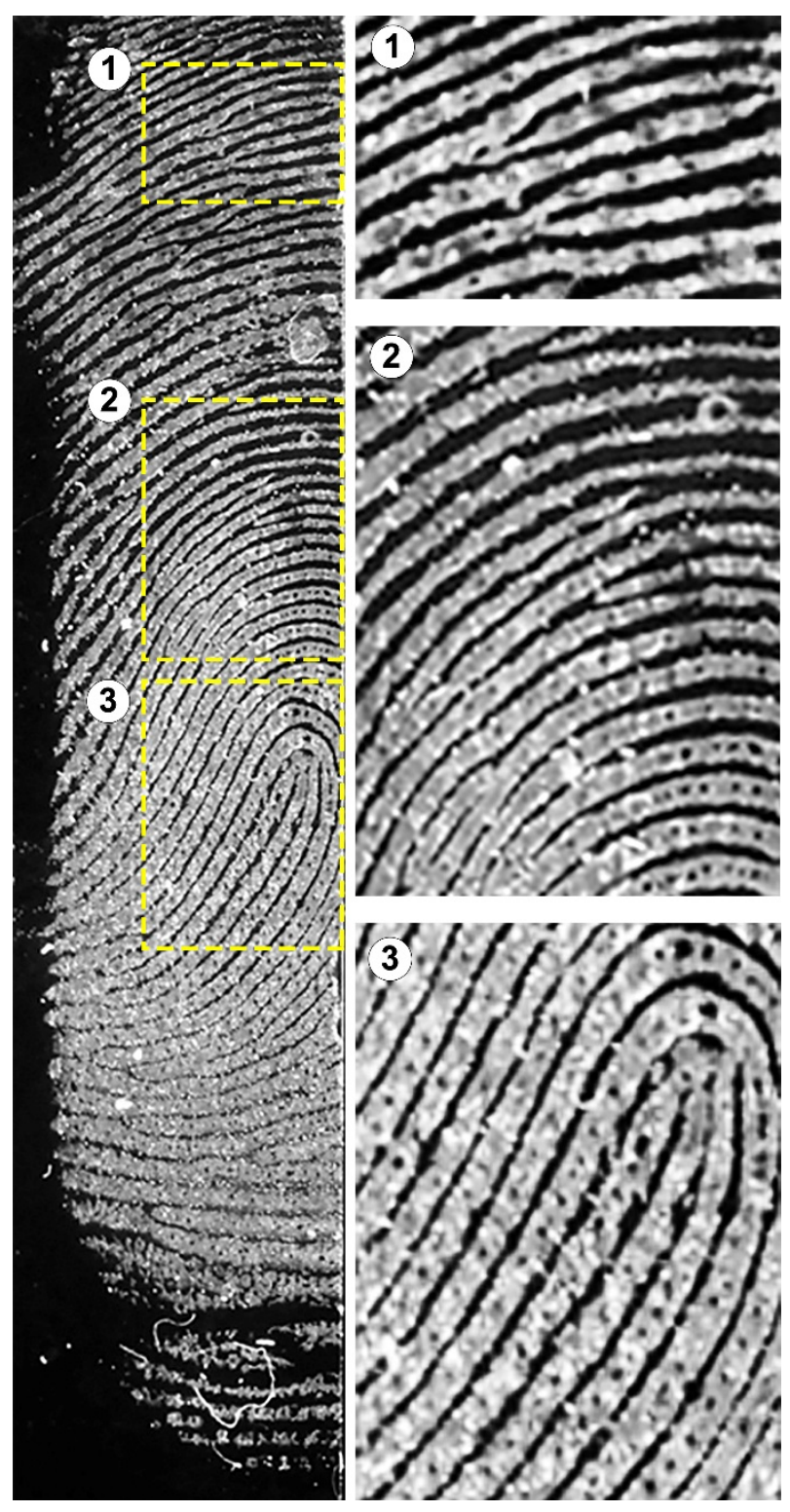

Figure 4. Developed natural latent fingermark (one male donor) deposited on a transparent sticky tape. The right side images are the different areas within the left side mark in higher magnification. The marks was illuminated at $350 \mathrm{~nm}$ and pictured through the deep red filter. See Table S1 for the photography conditions. The mark was shaken at $20 \mathrm{rpm}$ for $5 \mathrm{~min}$ in NAC-coated CIS-ZS QDs solution.

In conclusion, a safe innovative and straightforward procedure was developed for preparation and application of an aqueous working solution containing surface modified CIS-ZS core-shell
QDs for visualisation of latent fingermarks. Latent fingermarks on various challenging non-porous substrates were rapidly developed with high levels of ridge detail being observed. Being luminescent at deep red to NIR wavelength made it possible to eliminate the problem of dark, multi-coloured and multi-patterned backgrounds. However, issues remain in application to natural fingermarks on some challenging substrates such as polymer banknotes and cans. Further studies with a wider range of donors and substrates are required, as well as optimisation of the technique, including factors such as additional surface modification of the QDs, pH adjustment of the working solution and combination with other methods (such as cyanoacrylate fuming).

\section{Acknowledgements}

The authors thank all fingermark donors for their cooperation. This research has been conducted in accordance with the Curtin University human research ethics committee (approval number: HRE2016-0252). S.S. was supported by an Australian Postgraduate Award (APA) and Research Training Scheme (RTS) awarded from Curtin University. G.J. acknowledged ARC for funding support through the DECRA scheme (Project ID: DE160100589). There are no conflicts to declare.

Keywords: Quantum dots $\cdot$ heavy-metal-free $\cdot$ latent fingermarks $\cdot$ luminescence $\cdot$ red/near infrared

[1] a) S. Moret, A. Bécue, C. Champod, Nanotechnology 2014, 25, 425502; b) J. Dilag, H. J Kobus, A. V Ellis, Curr Nanosci. 2011, 7 153-159.

[2] a) A. Becue, A. A. Cantú, in Lee and Gaensslen's Advances in Fingerprint Technology, 3rd ed. (Ed.: S. R. Robert), CRC Press, Miami, 2012, pp. 307-380; b) M. J. Choi, A. M. McDonagh, P. Maynard, C. Roux, Forensic Sci. Int. 2008, 179, 87-97; c) J. Hai, T. Li, J. Su, W. Liu, Y. Ju, B. Wang, Y. Hou, Angew. Chem. Int. Ed. 2018, 57, 6786-6790; d) J. Wang, T. Wei, X. Li, B. Zhang, J. Wang, C. Huang, Q. Yuan, Angew. Chem. Int. Ed. 2014, 53, 16161620; e) P. Hazarika, D. A. Russell, Angew. Chem. Int. Ed. 2012, 51, 3524-3531; f) O. S. Wolfbeis, Angew. Chem. Int. Ed. 2009, 48, 2268-2269.

[3] a) E. Menzel, M. Takatsu, R. Murdock, K. Bouldin, K. Cheng, J. Forensic Sci. 2000, 45, 770-773; b) G. Jia, A. Sitt, G. B. Hitin, I. Hadar, Y. Bekenstein, Y. Amit, I. Popov, U. Banin, Nat. Mater. 2014, 13, 301-307; c) A. P. Alivisatos, Science 1996, 271, 933937; d) X. Peng, L. Manna, W. Yang, J. Wickham, E. Scher, A. Kadavanich, A. P. Alivisatos, Nature 2000, 404, 59.

[4] M. Algarra, K. Radotić, A. Kalauzi, D. Mutavdžić, A. Savić, J. Jiménez-Jiménez, E. Rodríguez-Castellón, J. C. E. da Silva, J. J. Guerrero-González, Anal. Chim. Acta 2014, 812, 228-235.

[5] a) J. Liu, Z. Shi, Y. Yu, R. Yang, S. Zuo, J. Colloid Interface Sci. 2010, 342, 278-282; b) X. Yu, J. Liu, S. Zuo, Y. Yu, K. Cai, R. Yang, Forensic Sci. Int. 2013, 231, 125-130.

[6] a) M. Bottrill, M. Green, ChemComm 2011, 47, 7039-7050; b) P. Wu, C. Li, J. Chen, C. Zheng, X. Hou, Appl. Spectrosc. Rev. 2012 47, 327-370.

[7] a) F. Gao, J. Han, C. Lv, Q. Wang, J. Zhang, Q. Li, L. Bao, X. Li, J. Nanoparticle Res. 2012, 14, 1191; b) Y. F. Wang, R. Q. Yang, Y. J. Wang, Z. X. Shi, J. J. Liu, Forensic Sci. Int. 2009, 185, 96-99. a) Y.-B. Zhao, Y.-j. Ma, D. Song, Y. Liu, Y. Luo, S. Lin, C. Liu, Anal. Methods 2017, 9, 4770-4775; b) C. Xia, X. Hai, X.-W. Chen, J.-H. Wang, Talanta 2017, 168, 269-278; c) H. A. Yadav, B. Eraiah, R. Basavaraj, H. Nagabhushana, G. Darshan, S. Sharma, B. D. Prasad, R. Nithya, S. Shanthi, J. Alloys Compd. 2017, 742, 1006-1018.

[9] a) S. Moret, A. Bécue, C. Champod, Forensic Sci. Int. 2013, 224, 101-110; b) C. Xu, R. Zhou, W. He, L. Wu, P. Wu, X. Hou, Anal. Chem. 2014, 86, 3279-3283. 
[10] a) V. Sharma, A. Das, V. Kumar, O. M. Ntwaeaborwa, H. C. Swart, J. Mater. Sci. 2013, 49, 2225-2234; b) P. Hazarika, S. M. Jickells, K. Wolff, D. A. Russell, Angew. Chem. Int. Ed. 2008, 47, 1016710170; c) J. Tan, L. Xu, T. Li, B. Su, J. Wu, Angew. Chem. Int. Ed. 2014, 53, 9822-9826; d) L. Xu, Y. Li, S. Wu, X. Liu, B. Su, Angew. Chem. Int. Ed. 2012, 51, 8068-8072.

[11] a) X. Jin, L. Dong, X. Di, H. Huang, J. Liu, X. Sun, X. Zhang, H. Zhu, RSC Adv. 2015, 5, 87306-87310; b) R. S. King, P. M. Hallett, D. Foster, Forensic Sci. Int. 2015, 249, e21-26; c) S. Chadwick, P. Maynard, P. Kirkbride, C. Lennard, A. McDonagh, X. Spindler, C. Roux, Forensic Sci. Int. 2012, 219, 208-214; d) P. Maynard, J. Jenkins, C. Edey, G. Payne, C. Lennard, A. McDonagh, C. Roux, Aust. J. Forensic Sci. 2009, 41, 43-62.

[12] a) A. Raevskaya, O. Rozovik, A. Novikova, O. Selyshchev, O. Stroyuk, V. Dzhagan, I. Goryacheva, N. Gaponik, D. R. Zahn, A. Eychmüller, RSC Adv. 2018, 8, 7550-7557; b) A. Raevskaya, O Rosovik, A. Kozytskiy, O. Stroyuk, V. Dzhagan, D. R. T. Zahn, RSC Adv. 2016, 6, 100145-100157; c) R. Xie, M. Rutherford, X. Peng, J. Am. Chem. Soc. 2009, 131, 5691-5697; d) L. Li, A Pandey, D. J. Werder, B. P. Khanal, J. M. Pietryga, V. I. Klimov, J. Am. Chem. Soc. 2011, 133, 1176-1179.

[13] a) H. Zhong, S. S. Lo, T. Mirkovic, Y. Li, Y. Ding, Y. Li, G. D. Scholes, ACS Nano 2010, 4, 5253-5262; b) Z. Pan, I. n. MoraSeró, Q. Shen, H. Zhang, Y. Li, K. Zhao, J. Wang, X. Zhong, J. Bisquert, J. Am. Chem. Soc. 2014, 136, 9203-9210; c) J. Du, Z. Du, J.-S. Hu, Z. Pan, Q. Shen, J. Sun, D. Long, H. Dong, L. Sun, X. Zhong, J. Am. Chem. Soc. 2016, 138, 4201-4209.

[14] a) B. Chen, H. Zhong, W. Zhang, Z. a. Tan, Y. Li, C. Yu, T. Zhai, Y. Bando, S. Yang, B. Zou, Adv. Funct. Mater. 2012, 22, 2081-2088; b) M. G. Panthani, V. Akhavan, B. Goodfellow, J. P. Schmidtke, L.
Dunn, A. Dodabalapur, P. F. Barbara, B. A. Korgel, J. Am. Chem. Soc. 2008, 130, 16770-16777.

[15] W. Zhang, X. Zhong, Inorg. Chem. 2011, 50, 4065-4072.

[16] a) B. Zhang, Y. Wang, C. Yang, S. Hu, Y. Gao, Y. Zhang, Y Wang, H. V. Demir, L. Liu, K. T. Yong, PCCP 2015, 17, 2513325141; b) S. Liu, H. Zhang, Y. Qiao, X. Su, RSC Adv. 2012, 2 , 819-825; c) W.-W. Xiong, G.-H. Yang, X.-C. Wu, J.-J. Zhu, ACS Appl. Mater. Interfaces 2013, 5, 8210-8216; d) L. Li, T. J. Daou, I. Texier, T. T. Kim Chi, N. Q. Liem, P. Reiss, Chem. Mater. 2009, 21, 2422-2429; e) T. Pons, E. Pic, N. Lequeux, E. Cassette, L. Bezdetnaya, F. Guillemin, F. Marchal, B. Dubertret, ACS Nano 2010, 4, 2531-2538

[17] O. Yarema, M. Yarema, V. Wood, Chem. Mater. 2018, 30, 14461461.

[18] a) A. Becue, S. Moret, C. Champod, P. Margot, Forensic Sci. Int 2009, 191, 36-41; b) Y. Chen, S. Li, L. Huang, D. Pan, Inorg Chem. 2013, 52, 7819-7821.

[19] a) X. Peng, M. C. Schlamp, A. V. Kadavanich, A. P. Alivisatos, J. Am. Chem. Soc. 1997, 119, 7019-7029; b) Z. Pan, I. Mora-Seró, Q. Shen, H. Zhang, Y. Li, K. Zhao, J. Wang, X. Zhong, J. Bisquert, J. Am. Chem. Soc. 2014, 136, 9203-9210; c) M. Gannouni, M. Kanzari, Appl. Surf. Sci. 2011, 257, 10338-10341.

[20] H. Bao, Y. Gong, Z. Li, M. Gao, Chem. Mater. 2004, 16, 38533859.

[21] IFRG, J. Forensic Identif. 2014, 64, 174-200

[22] L. F. Prescott, A. Ballantyne, A. T. Proudfoot, J. Park, P. Adriaenssens, Lancet 1977, 310, 432-434. 
A novel green, safe and convenient technique was introduced to develop latent fingermarks on different challenging substrates using red/ near-infrared luminescent heavymetal-free Cu-In-S/ZnS QDs synthesised in water.

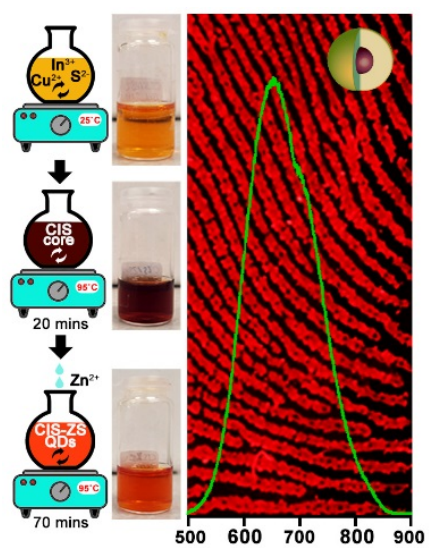

Sorour Shahbazi, ${ }^{[a]}$ Braden Grant, ${ }^{[a]}$ Dechao Chen, ${ }^{[a]}$ Thomas Becker, ${ }^{[a]}$ Guohua Jia, ${ }^{*[a]}$ Simon W. Lewis ${ }^{*[a]}$

Red-Near Infrared Luminescence

Detection of Latent Fingermarks with Heavy-Metal-Free Quantum Dots 